\title{
Analisa Pengaruh Pemeliharaan Machinery Dari Annual Survey Ke Intermediate Survey Dengan Menerapkan Maintanance Management System
}

\author{
${ }^{1}$ Hadi Prasutiyon, ${ }^{2}$ Firdaus Dedy Kurniawan \\ ${ }^{1,2}$ Teknik Sistem Perkapalan, Universitas Hang Tuah Surabaya, Indonesia \\ hadi.prasutiyon@hangtuah.ac.id, firdausdywan@gmail.com
}

\begin{tabular}{l} 
ARTICLE INFO \\
\hline Article History: \\
Received : $08-04-2021$ \\
Revised : 20-04-2021 \\
Accepted : $01-05-2021$ \\
Online : $04-05-2021$ \\
Keywords: \\
Annual Survey System; \\
Intermediate Survey \\
System; Maintenance \\
Management System.
\end{tabular}

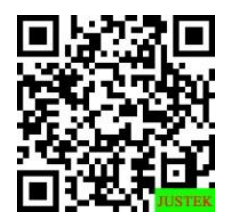

\begin{abstract}
Abstract: In the field of shipping, maintenance of ships needs to be done to maintain the durability of the ship so that the life time is long so that the level of smooth productivity is not disturbed due to damage to the ship. Apart from that, regular surveys are also conducted to check the condition of the ship as well as to collect data on ships in the class. Ship maintenance in ensuring the implementation of the planned maintenance system (PMS) on the ship must meet the requirements. The survey studied in this study is about maintenance methods that are considered inaccurate in selecting the method of maintaining machinery and not applying a management which has an impact on work effectiveness. The research method used is a periodic survey method accompanied by implementing a Maintenance Management System tailored to the needs of the company. So that there are two main studies, namely the Annual Survey System and the Intermediate Survey System. This is to determine the right method for the company in calculating in terms of material, cost and time as well as maintenance management for each activity in order to create more effective work.
\end{abstract}

\begin{abstract}
Abstrak: Pada bidang perkapalan perawatan kapal perlu dilakukan untuk mempertahankan ketahanan kapal agar life time nya lama sehingga tingkat produktifitas lancar tidak terganggu akibat adanya kerusakan pada kapal. Selain itu juga dilakukan survey secara berkala untuk pengecekan kondisi kapal sekaligus pendataan kapal pada kelas. Perawatan kapal dalam menjamin terlaksananya pelaksanaan sistem pemeliharaan terencana (PMS, Planned Maintenance System) di kapal harus memenuhi persyaratan. Survey yang dikaji dalam penelitian ini adalah mengenai metode pemeliharaan yang dianggap belum tepat dalam pemilihan metode pemeliharaan machinery dan tidak diterapkanya sebuah management yang berdampak kepada efektivitas kerja. Metode penelitian yang digunakan adalah metode survey periodik disertai dengan menerapkan Maintenance Management System yang disesuaikan dengan kebutuhan perusahaan. Sehingga didapat dua kajian utama yakni Annual Survey System dan Intermediate Survey System. Hal ini untuk mengetahui metode yang tepat bagi perusahaan dalam menghitung dari segi material, biaya dan waktu serta pengelolaan pemeliharaan pada setiap kegiatan agar tercipta pekerjaan yang lebih efektif.
\end{abstract}




\section{A. LATAR BELAKANG}

Pada era globalisasi saat ini, dimana perkembangan industri berkembang pesat,dan Indonesia merupakan negara berkepulauan terbesar. Menjadikannya sebagai wilayah strategis dalam mengembangkan usaha industri jasa transportasi kapal laut. Kapal merupakan transportasi yang sarat akan regulasi (aturan). Sejak kapal dipesan untuk dibangun hingga kapal beroperasi dan mendapat perawatan, selalu ada peraturan yang harus dipatuhi dan di dalam proses pelaksanaannya pun selalu dilakukan pengawasan (Iriani et al., 2011). Hal tersebut dilakukan sebagai upaya mewujudkan keadaan terpenuhinya persyaratan keselamatan dan keamanan yang menyangkut angkutan di perairan.

Perawatan kapal merupakan salah satu hal terpenting dalam menjaga kapal agar selalu berada dalam kondisi yang baik dan siap ketika akan beroperasi. Perawatan kapal dapat diartikan sebagai suatu usaha atau kegiatan yang dilakukan terhadap kapal untuk mencegah terjadinya kerusakan dan mengembangkan kepada kondisi yang lebih baik. Pemeliharaan kapal akan dilakukan ketika terjadi sebuah kerusakan,karena kapal yang terus bertambah tua dan rusaknya beberapa bagian dari konstruksi kapal,sehingga mengakibatkan berkurangnya kemampuan kapal dalam beroprasi (Jaka Purnama, Yosua Anggara Putra, 2015). Keselamatan dan keamanan pengoperasian kapal merupakan kondisi terpenuhinya persyaratan atas kewajiban yang harus dipenuhi dari kelaiklautan kapal (seaworthiness) yang sesuai dengan Undang-Undang Nomor 17 tahun 2008 tentang Pelayaran pasal 17 ayat 2 yang meliputi keselamatan kapal, pencegahan pencemaran dari kapal, pengawakan kru kapal, garis muat kapal dan pemuatan, kesejateraan kru kapal dan kesehatan penumpang, status hukum kapal, manajemen keselamatan dan pencegahan. pencemaran dari kapal serta manajemen kapal (Taufik \& Septyani, 2016).

Untuk meningkatkan kinerja pengoperasian kapal, dan mengurangi angka kecelakaan yang disebabkan oleh kapal tidak layak laut, sebelum kapal beroperasi harus dilakukan pemeriksaan. Di Indonesia ada beberapa pihak yang melakukan pemeriksaan antara lain syahbandar atau Port State Control (PSC), Biro Klasifikasi, perusahaan asuransi, pemilik muatan (tanker). Berdasarkan pemeriksaan dari pihak syahbandar atau Port State Control (PSC) dan biro klasisifikasi ada beberapa jenis pemeriksaan diatas kapal. Jenis pemeriksaan ini tergantung dari jenis survey, bagian yang di survey, dan waktu survey. Misalnya annual survey, dan Intermediate survey. Annual survey dilakukan setiap tahun merupakan pemeriksaan umum dari bagian yang berkaitan dengan sertifikat untuk memastikan bahwa peralatan yang digunakan masih berfungsi dengan baik di laksanakan setiap tahun (Alwi, 2016).

Periodical/Intermediate survey atau survey berkala yaitu pemeriksaan yang berkaitan dengan sertifikat untuk memastikan bahwa peralatan yang digunakan masih dalam kondisi baik. Pemeriksaan ini lebih detail dibandingkan dengan pemeriksaan tahunan. Survey ini dilaksanakan setiap 2,5 tahun sejak peresmian kapal dan tiap pembaharuan klas. Dalam hal ini peran penting Biro Klasifikasi sebagai badan hukum yang mempunyai wewenang mengawasi,memeriksa,dan memberi perijinan dalam 
pengoperasian kapal secara baik,maka dibutuhkan waktu yang tepat dalam menentukan kapan pemeliharaan atau reparasi itu dilakukan. Seperti diketahui, bahwa pemeliharaan memerlukan penanganan yang baik agar kapal tersebut tetap dalam kondisi prima, sehingga perusahaan pelayaran akan selalu berusaha mencari solusi terbaik untuk penanganan yang tepat pada perawatan kapal sehingga menjadi lebih efisien dalam pengerjaannya (Syahruddin, 2012).

Dalam beberapa kejadian terdapat masalah dalam menentukan pemeliharaan machinery. Khususnya sistem survey yang diterapkan oleh badan klasifikasi. Pemeliharaan mesin secara menyeluruh adalah dengan melakukan Survey periodik, dan secara rutin harus dilakukan pemeliharaan oleh pihak kapal dan manajemen di darat. Survey periodik biasanya menggunakan metode Annual Survey system dan Intermediate survey system (Jaka Purnama, Yosua Anggara Putra, 2015). Tujuan dari melaksanakan survey itu sendiri adalah untuk mempertahankan atau menjaga performance kapal, dan untuk pengecekan ketahanan atau kekuatan pada kapal (strengthness), agar lifetime suatu kapal dapat berjalan secara optimal.

\section{B. METODE PENELITIAN}

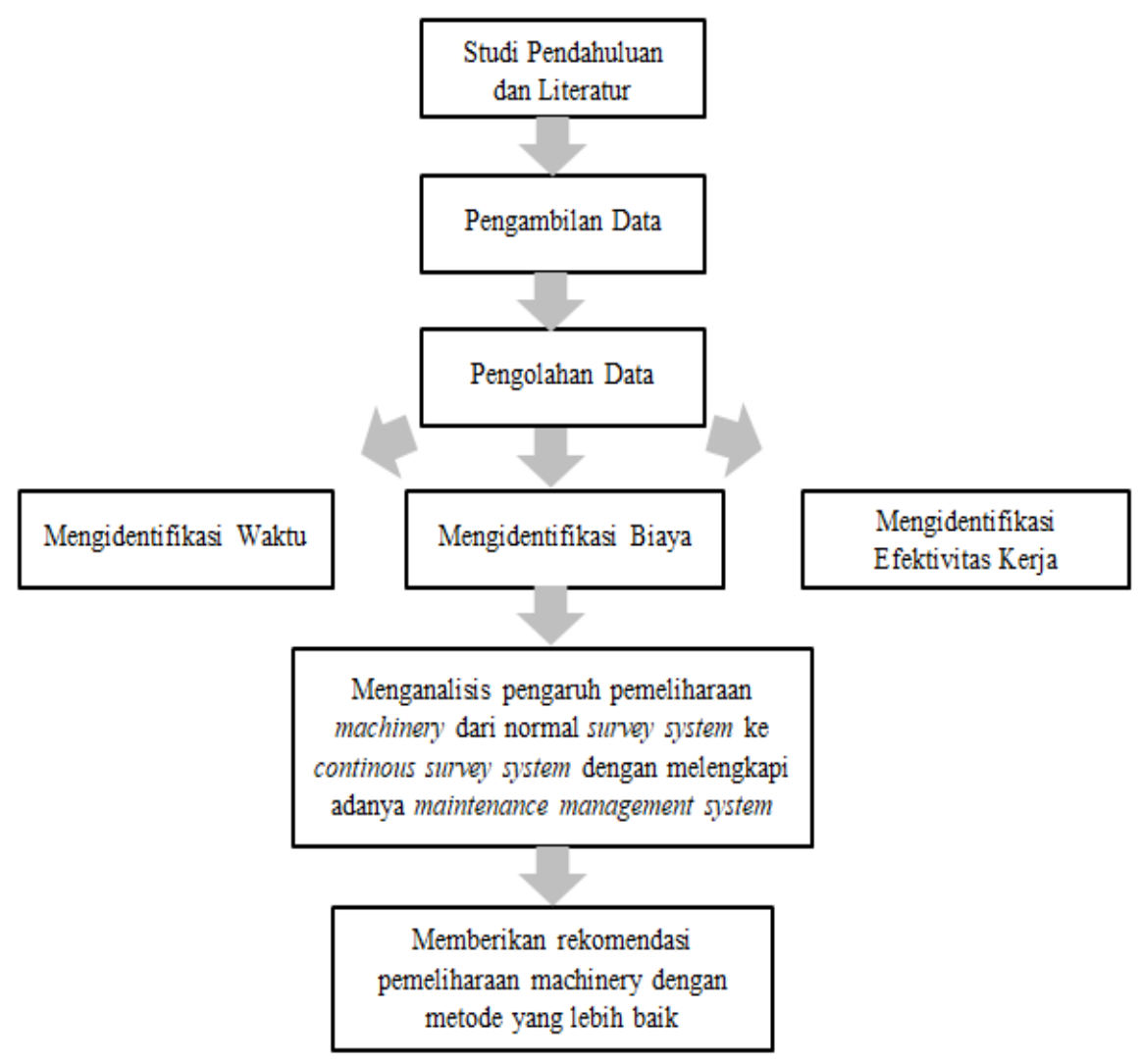

Gambar 1. Diagram Alir Penelitian

Dalam mengkaji penerapan normal survey system, continous survey system, dan machinery maintenance report pada pemeliharan machinery, memang ada kelebihan dan kekurangan (Yusuf, 2016). Pada normal survey system atau continuous survey 
system terdapat perbedaan terhadap waktu dan biaya yang timbul. Begitu juga mengenai management maintenance system yang sanagat berpengaruh terhadap efektivitas kerja, sehingga perlu pertimbangan terhadap penerapannya. Dalam tahap ini survei dilakukan di galangan dimana kapal sedang melakukan pemeliharaan mesin dan data yang diambil meliputi: (1) machinery particulars; (2) machinery maintenance list dan (3) machinery maintenance reports

Pengolahan data dilakukan dengan menggunakan software berupa spreadsheet dari microsoft excel. Dalam mengidentifikasi waktu dan biaya ditetapkan rentang waktu selama lima tahun, dimana hal ini bisa saja terjadi pada spesial survey, normal survey atau continous survey. Waktu dan biaya ini dapat diidentifikasi dari maintanance reports selama berlangsungannya pemeliharaan mesin tersebut. Sedangkan pengaruh terhadap efektivitas kerja apabila kegiatan pemeliharaan machinery menerapkan sebuah maintenance management system yang sebelumnya tidak diterapkan, maka dengan adanya analisis ini diharapkan dapat membantu menghasilkan keputusan yang akan membantu meningkatkan kinerja pekerja yang cekatan dan sesuai dengan prosedur perusahaan yang terstruktur dan terencana dengan baik agar memudahkan dalam proses pengontrolan (Kusuma, 2015). Disamping itu juga perlu diadakan analisa apabila proses pemeliharaan machinery secara normal survey sistem diubah kedalam continuous survey sistem. Dari sinilah akan diketahui hal-hal yang berkaitan dengan budget dan pengelolaan keuangan yang ada di lapangan khususnya waktu dan man power di kapal. Diharapkan dengan mengetahui pengaruh dari perubahan metode tersebut mampu menghasilkan keputusan yang tepat yang akan direkomendasikan kepada pihak yang terkait mengenai penggunaan normal survey dan continuous survey, serta maintenance management system (Imanuell \& Lutfi, 2019).

\section{HASIL DAN PEMBAHASAN}

Sebelum membahas tentang pengertian annual survey sendiri untuk sebelumnya kita harus pahami arti dari "Class" itu sendiri. Class merupakan badan yang bertugas melakukan pengelasan kapal niaga. Tugas dari badan ini meliputi pengawasan atas pembangunan kapal baru dan kapal yang memang sedang beroperasi di suatu kawasan, serta memberikan sertifikasi kepada kapal-kapal yang telah lulus dari penilaian tersebut. Tujuannya untuk memastikan bahwa suatu kapal memiliki standar keselamatan yang layak atas awak beserta muatannya. Dasar penilaian klasifikasi suatu kapal sendiri terdiri dari International Convention on Load Lines (ILCC), International Convention for the Safety of Life at Sea (SOLAS), IMO Codes, Convention of the Labour Organization Office (ILO) dan International Convention for the Prevention of Pollution from Ships (MARPOL).

IMO adalah salah satu badan PBB yang mengurusi bidang kemaritiman, sebagai badan khusus PBB, IMO menetapkan standar global untuk keselamatan,keamanan, dan kinerja lingkungan pelayaran internasional. Juga untuk menciptakan kerangka peraturan bagi industri perkapalan yang adil dan efektif sehingga dapat diadopsi dan diimplementasikan secara universal. ISM Code merupakan standar Internasional yang 
digunakan untuk Sistem Manajemen Keselamatan dimana bertujuan untuk menjamin bahwa perusahaan memberi pelayanan yang memenuhi persyaratan yang ditetapkan, yaitu kapal dapat beroperasi dengan "selamat" dan mencegah terjadinya"pencemaran lingkungan". Biro Klasifikasi adalah Badan Hukum yang bergerak dalam bidang jasa yang mengurus permasalahan kelas kapal, baik kapal yang sedang dibangun, sudah dibangun atau yang sedang beroperasi yang berkaitan dengan konstruksi badan kapal, mesin kapal, termasuk permesinan dan peralatan lainnya.

Pemeliharaan dan Perbaikan, merupkan kegiatan yang bertujuan untuk merawat peralatan atau fasilitas agar tetap dalam kondisi yang stabil dan prima serta memperbaiki bagian yang mengalami kerusakan agar kegiatan operasi dapat berjalan kembali sesuai dengan yang direncanakan. Sistem perawatan mengacu pada sistem yang diterapkan class pada kapal tersebut. Dimana harus mengikuti prosedur perawatan Renewal Survey secara berkala, yaitu setiap 5 tahun harus overhaul baik untuk setiap unit atau untuk setiap part, seperti :Normal Survey System, Continuous Survey System, dan Planned Maintenance Survey System. Dalam manual book terdapat jadwal untuk pemeliharaan mesin, beberapa tabel yang berisikan bagian-bagian mesin dan berapa lama jam kerja mesin tersebut agar dapat dilakukan pemeliharaan secara berkala. Dengan adanya jadwal pemeliharaan mesin diatas yang terdapat pada masing-masing manual book mesin, dapat menjadi referensi dalam membuat sebuah maintenance management system untuk mesin tersebut. Juga dalam melakukan overhaul pada mesin, akan dibutuhkan waktu untuk melakukan proses tersebut. Terdapat banyak part pada mesin dan berbeda-beda waktu yang dibutuhkan untuk melakukan perbaikan terhadap masing-masing part tersebut. Terdapat juga beberapa tabel yang berisikan dengan part, banyaknya pekerja yang mengerjakan dan berapa lama waktu yang dibutuhkan oleh pekerja untuk melakukan overhaul untuk satu part dari mesin.

Tabel 1. Waktu Pengerjaan Overhaul Main Engine.

\begin{tabular}{|c|c|c|c|c|c|}
\hline \multicolumn{6}{|c|}{ Dierth a ul Main Engine } \\
\hline \multirow{2}{*}{ № } & Descrintion & Time (Hour) & \multirow{2}{*}{ Manpower } & \multirow{2}{*}{ Working hou } & \multirow{2}{*}{ Manhour } \\
\hline & Ecuriptiont & & & & \\
\hline \multirow{4}{*}{1} & Cyinder Head & & \multirow{4}{*}{2} & \multirow{4}{*}{8} & \multirow{4}{*}{16} \\
\hline & 2) Air, FO, LO pipes & & & & \\
\hline & b) lntake balle & & & & \\
\hline & c) Exhaust valie & & & & \\
\hline \multirow{4}{*}{2} & Piston & & \multirow{8}{*}{2} & \multirow{8}{*}{8} & \multirow{8}{*}{16} \\
\hline & a) Piston compression ring & & & & \\
\hline & 6) Piston oil ring & & & & \\
\hline & c) Piston Pin & & & & \\
\hline \multirow{4}{*}{3} & Connecting Rod & & & & \\
\hline & 2 Connecting rod bussing & & & & \\
\hline & 6) Bearing Insert (upper) & & & & \\
\hline & (c) Bearing Insert (lower) & & & & \\
\hline 4 & $\begin{array}{l}\text { Cyinder Liner } \\
\end{array}$ & & \multirow{5}{*}{2} & \multirow{5}{*}{5} & \multirow{5}{*}{10} \\
\hline \multirow{4}{*}{5} & bumal and Bearing & & & & \\
\hline & Main journal & & & & \\
\hline & 6) Main bearing jurnal & & & & \\
\hline & Crank pin journal & & & & \\
\hline & & & 6 & 21 & 42 \\
\hline
\end{tabular}


Tabel 2. Waktu Pengerjaan Overhaul Auxiliary Engine.

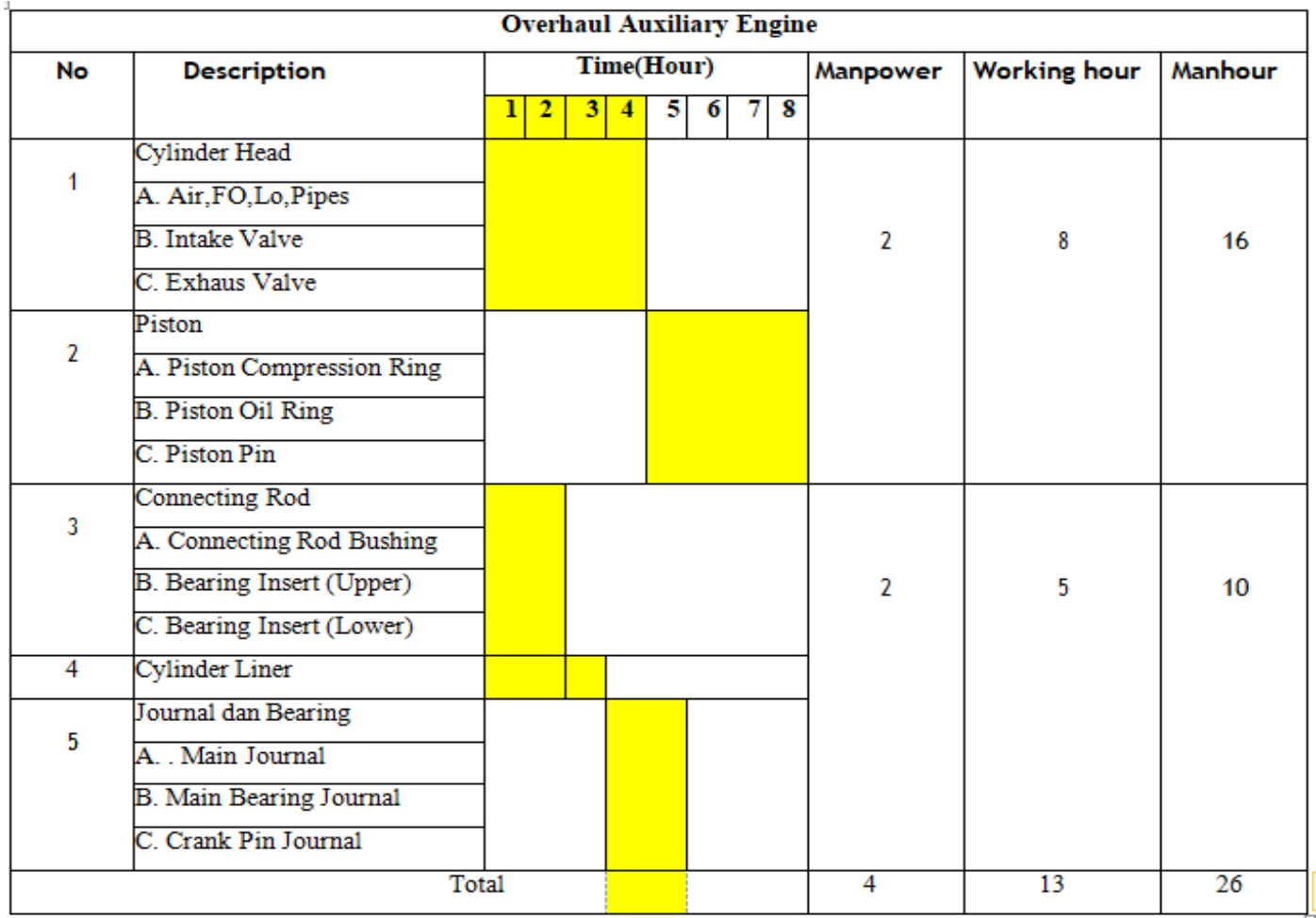

Dari data diatas dapat ditarik kesimpulan bahwa pekerjaan untuk melakukan overhaul untuk satu part dari mesin membutuhkan waktu selama 21 jam untuk main engine dan 13 jam untuk auxiliary engine. Maintenance Management System, pada dasarnya dalam perancangan sebuah system memiliki sebuah alur agar sistem tersebut berjalan sesuai dengan kebijakan yang akan diterapkan.Maksud dari penjelasan alur diatas adalah tentang sebuah maintenance management system. Dimana alur tersebut didapat dari proses penelitian yang bersumber dari manual book mesin yang dikeluarkan perusahaan pembuat, yaitu: Table Maintenance list, Table tool lis danTable Specification of main accessories and system data. Dari adanya data-data tersebut dibuatlah sebuah rangkuman pekerjaan menjadi sebuah pedoman kerja dalam pemeliharaan mesin kapal. Pedoman kerja tersebut terdiri dari beberapa prosedur kerja yang akan dilakukan dalam pemeliharaan, yaitu jadwal pemeliharaan mesin,prosedur kerja pemeliharaan mesin, prosedur permintaan sparepart mesin serta prosedur pencatatan laporan pemeliharaan mesin.

Dalam proses perubahan pemeliharaan machinery dari metode Annual Survey ke Intermediate Survey, terdapat beberapa pengaruh dalam pelaksanaanya yang meliputi masalah biaya dan waktu. Dalam masalah biaya, terlihat bahwa ada beberapa pengaruh terhadap perusahaan kapal dalam mengeluarkan dana untuk melakukan pemeliharaan. Terdapat beberapa pilihan untuk mengeluarkan biaya dalam pemeliharaan, yaitu dengan menggunakan jasa kontraktor atau menggunakan jasa crew kapal sendiri. Dalam hal waktu, pengaruh yang ditimbulkan dalam pemeliharaan sama seperti pengaruh yang ditimbulkan dalam mempengaruhi cara mengeluarkan biaya. Dalam masalah waktu, perbedaan tersebut antara Annual Survey dan Intermediate Survey adalah dalam cara meluangkan waktu untuk pemeliharaan sebagaimana terlihat pada tabel dibawah ini. 
Tabel 3. Analisis Waktu Antara Annual Survey System dengan Intermediate Survey System.

\begin{tabular}{|c|c|c|c|}
\hline \multicolumn{2}{|c|}{ Overhaul Main Engine } \\
\hline \multirow{2}{*}{ No } & \multirow{2}{*}{ Tahun } & Jumlah Cylinder \\
\cline { 3 - 5 } & & 0 & Continuous Survey System \\
\hline 1 & 1 & 0 & 2 \\
\hline 2 & 2 & 0 & 2 \\
\hline 3 & 3 & 0 & 1 \\
\hline 4 & 4 & 8 & 1 \\
\hline 5 & 5 & 0 & 2 \\
\hline
\end{tabular}

Pada dasarnya pekerjaan dikerjakan untuk menghasilkan sesuatu dalam mencapai tujuan perusahaan sesuai dengan kebijakan, perencanaan yang dapat diukur tingkat pencapaiannya. Sehingga tingkat efektivitas kerja pada tiap perusahaan tidak akan sama karena beberapa faktor dalam aspek yang dinilai. Namun pada dasarnya objek yang menjadi sasaran dalam hal ini yakni para pekerja, dimana pekerja merupakan salah satu unsur dalam menentukan tercapai atau tidaknya tujuan organisasi atau perusahaan. Maintenance management system adalah salah satu cara untuk membantu mengelola proses pemeliharaan dalam organisasi dimana tentunya dapat terkontrol, terukur, dan terencana. Maintenance management system juga merupakan kegiatan pengorganisasian operasi perawatan yang bertujuan untuk memberikan pandangan umum mengenai perawatan. Pada dasarnya hal ini dilakukan oleh pekerja untuk memudahkan dalam melakukan pekerjaan. Keterkaitan keduanya dapat kita ketahui dari berbagai pandangan para ahli yang mengungkapkan bahwa pada dasarnya perilaku individu akan menpengaruhi kinerja dari individu itu sendiri.

Dalam hal ini kita ketahui bahwa salah satu perilaku individu tersebut mengikuti kebijakan maintenance management system. Ketika pekerja mengikuti kebijakan maintenance management system dengan baik maka seorang pekerja akan melaksanakan pekerjaan sesuai dengan kebijakan perusahaan tersebut. Salah satu kebijakan perusahaan akan berisi mengenai job description pekerja, sehingga pekerja akan bekerja sesuai dengan tugas dan kewajibannya pada bidang yang telah ditentukan. Ketika seorang pekerja fokus pada pekerjaan yang dia kerjakan, maka tingkat kinerja yang akan dia capai dapat lebih tinggi bahkan melebihi ekspektasi yang telah ditentukan. Karena maintenance management system akan mendorong dia untuk selalu patuh pada aturan dan bekerja sesuai dengan pembagian tugasnya. Dalam hal ini maintenance management system diharapkan mampu memberikan dampak yang baik terhadap kinerja pekerja karena mampu menghasilkan pekerja yang bekerja efektif dan berkontribusi tinggi dalam perusahaan. 


\section{SIMPULAN DAN SARAN}

Berdasarkan dari hasil analisis pengaruh pemeliharaan machinery dari Annual Survey ke Intermediate survey dengan melengkapi adanya maintenance management system didapatkan bahwa pengaruh perubahan metode pemeliharaan dari normal survey system ke continuous survey system terhadap perusahaan dalam hal biaya dan waktu, perusahaan akan mengeluarkan dana untuk pemeliharaan machinery secara bersekala selama dua setengah tahun.Sedangkan perilaku individu akan mempengaruhi kinerja pekerja itu sendiri. Maintenance management system memberikan prosedur kerja yang baik dan terstruktur sesuai dengan kebijakan perusahaan sehingga menuntut para pekerja untuk selalu patuh terhadap prosedur kerja dan sesuai dengan job description para pekerja agar lebih efektif. Selain itu didapat record setiap kegiatan yang telah dilakukan oleh pekerja dan terdokumentasi dengan lengkap yan dapat dipertanggung jawabkan. Semua kegiatan tersebut merupakan usaha untuk memperbaiki system kerja yang baik dimana dampaknya akan berguna terhadap kinerja pegawai.

\section{UCAPAN TERIMA KASIH}

Ucapan terimakasih saya sampaikan kepada Bapak Mayor Laut Yayan Yuliandri dari Fasharkan Lantamal V Surabaya yang memberikan bimbingan dan fasilitas bengkel sekaligus memberikan ide atas terbuatnya paper ini. Juga saya ucapkan terimaksih kepada Bapak Urip Prayogi Kaprodi TSP UHT yang telah memberi petunjuk dan bimbingan atas terlaksananya penelitian ini.

\section{REFERENSI}

Alwi, M. R. (2016). Reliability Centered Maintenance Dalam Perawatan F.O. Service Pump Sistem Bahan Bakar Kapal Ikan. Jurnal Riset Dan Teknologi Kelautan (JRTK), 14(1), 77-86.

Apriliandi, Haski (2013). Perancangan Planned Maintenance System Pada Mesin Kapal Jenis Diesel 2 Langkah Dengan Jumlah Silinder Tujuh Dan Bertenaga 15820 KW. Depok.

E wahyu A, S Nugroho, T Wuruk P. 2018. Penerapan Tehnologi Informasi Pada System Pemeliharaan Kapal Terencana. Jurnal Kelautan. Vol 11, No. 1. http:/doi.org/10.21107/jk.v11j1.3145

Imanuell, R., \& Lutfi, M. (2019). Analisa Perawatan Berbasis Keandalan Pada Sistem Bahan Bakar Mesin Utama KMP. Bontoharu. JST (Jurnal Sains Terapan), 5(1). https://doi.org/10.32487/jst.v5i1.540

Iriani, Y., Rahmadi, E. S., Industri, J. T., Tekillk, F., \& Widyatama, U. (2011). Usulan Waktu Perawatan Berdasarkan Keandalan Suku Cadang Kritis Bus di Perum Damri Bandung. Proceedings 6th Nalional Lnduslrial Engineering Conference (NIEC-6), 171-178.

Jaka Purnama, Yosua Anggara Putra, M. K. (2015). Metode Age Replacement Digunakan Untuk Menentukan Interval Waktu Perawatan Mesin Pada Armada Bus. Seminar Nasional Sains Dan Teknologi Terapan III 2015 Institut Teknologi Adhi Tama Surabaya ISBN, 115-126.

Kusuma, I. P. A. I. (2015). Studi analisa kehandalan dan jadwal perawatan sistem bahan bakar di kapal dengan pemodelan dinamika sistem. Seminar Nasional Sains Dan Teknologi Terapan III, 533-542.

Muhtadi, A., Pribadi, T. W., \& Baihaqi, I. (2016). Studi Implementasi Reparasi Kapal 
Berbasis Keandalan untuk Galangan Kapal. Jurnal Teknik ITS, 5(1), 1-7. https://doi.org/10.12962/j23373539.v5i1.15789

Sabine Knapp and Philip Hans, 2006. Analysis of The Marine Inspection Regimes- Are Ship Over Inspected. Economic Institute, Erasmus University Roterdam.

Siagian, D. C., Napitupulu, H., \& Siregar, I. (2013). Usulan Perawatan Mesin Berdasarkan Keandalan Spare Part Sebagai Solusi Penurunan Biaya Perawatan Pada Pt. Xyz. Jurnal Teknik Industri USU, 3(5), 47-52.

Syahruddin. (2012). Analisis Sistem Perawatan Mesin Menggunakan Metode Reliability Centered Maintenance (RCM)Sebagai Dasar Kebijakan Perawatan yang Optimal di PLTD "X." Jurnal Tekhologi Terpadu, 1(7), 42-49.

Taufik, T., \& Septyani, S. (2016). Penentuan Interval Waktu Perawatan Komponen Kritis pada Mesin Turbin Di PT Pln (Persero) Sektor Pembangkit Ombilin. Jurnal Optimasi Sistem Industri, 14(2), 238. https://doi.org/10.25077/josi.v14.n2.p238-258.2015

Yusuf, Z. A. (2016). Analisa Perawatan Berbasis Resiko Pada Sistem Pelumas Km. Lambelu. Jurnal Riset Dan Teknologi Kelautan (JRTK), 14(1), 129-140. 